Florida International University FIU Digital Commons

4-6-1995

\title{
Worry, anxiety and their relation in a clinical sample of children with anxiety disorders
}

Steven Kent Cumbo

Florida International University

DOI: $10.25148 /$ etd.FI14061565

Follow this and additional works at: https://digitalcommons.fiu.edu/etd

Part of the Psychology Commons

\section{Recommended Citation}

Cumbo, Steven Kent, "Worry, anxiety and their relation in a clinical sample of children with anxiety disorders" (1995). FIU Electronic Theses and Dissertations. 2689.

https://digitalcommons.fiu.edu/etd/2689

This work is brought to you for free and open access by the University Graduate School at FIU Digital Commons. It has been accepted for inclusion in FIU Electronic Theses and Dissertations by an authorized administrator of FIU Digital Commons. For more information, please contact dcc@fiu.edu. 
FLORIDA INTERNATIONAL UNIVERSITY

Miami, Florida

WORRY, ANXIETY, AND THEIR RELATION IN A CLINICAL SAMPLE OF CHILDREN WITH ANXIETY DISORDERS

A thesis submitted in partial satisfaction of the requirements for the degree of MASTER OF SCIENCE

IN

PSYCHOLOGY

by

Steven Kent Cumbo 
To: $\frac{\text { Dean Arthur } W \text {. Herriott }}{\text { College of Arts \& Sciences }}$

This thesis, written by steven Kent Cumbo, and entitled Worry, Anxiety, and Their Relation in a Clinical Sample of Children with Anxiety Disorders, having been approved in respect to style and intellectual content, is referred to you for judgement.

We have read this thesis and recommend that it be approved.

Scott L. Fraser

William M. Kurtines

Wendy K. Silverman, Major Professor

Date of Defense: April 6, 1995

The thesis of Steven Kent Cumbo is approved.

Dean Arthur $W$. Herriott College of Arts and Sciences

Dr. Richard L. Campbell

Dean of Graduate Studies

Florida International University, 1995 
${ }^{\circ}$ COPYRIGHT 1995 By Steven Kent Cumbo

All rights reserved

iii 
I dedicate this thesis to my wife, family, and friends. 


\section{ACKNOWLEDGMENTS}

I wish to thank the members of my committee for their flexibility, understanding, and cooperation. Without these qualities, no project of this nature could be successfully undertaken. To scott Fraser, in particular, I want to thank for his support and friendship during this process. In addition, I would like to offer a thanks to Bill Kurtines for making the time to be a part of this project. Finally, a very special thanks to Wendy Silverman for her insights, feedback, and direction. 
ABSTRACT OF THE THESIS

WORRY, ANXIETY, AND THEIR RELATION IN A CLINICAL

SAMPLE OF CHILDREN WITH ANXIETY DISORDERS

by

Steven Kent Cumbo

Florida International University, 1995

Miami, Florida

Professor Wendy K. Silverman, Major Professor

Worry is the hallmark feature of the anxiety disorders in children and adolescents. Little information, however, is available on childhood worry, and when worry may lead to functional impairment. The number, frequency, intensity, and areas of worry were examined in a clinic sample of children with anxiety disorders $(n=59)$ using a structured data gathering procedure. Findings revealed that number of worry increased with age; severity decreased with age. An interaction between age and gender was also found. No differences were found for frequency or intensity. The most common areas of worry were School, Health, and Personal Harm. A link between worry and anxiety was also established as children with Overanxious Disorder (which is characterized by excessive worry) scored higher on all worry parameters relative to children with other types of anxiety disorders. The theoretical and clinical implication of these finding are discussed. 
I. INTRODUCTION $\ldots \ldots \ldots \ldots \ldots \ldots \ldots \ldots \ldots \ldots \ldots \ldots$

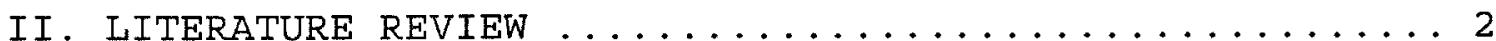

Theoretical Issues ................... 2

Clinical Issues .....................

Developmental Issues $\ldots \ldots \ldots \ldots \ldots \ldots \ldots \ldots \ldots$

Purpose .............................

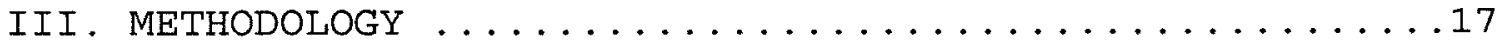

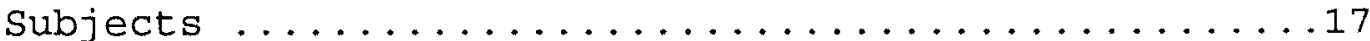

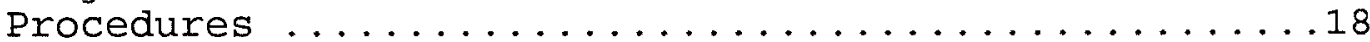

Assessment of Childhood Worry .................

Training of Interviewers ..............19

Description of Interviewer ............19

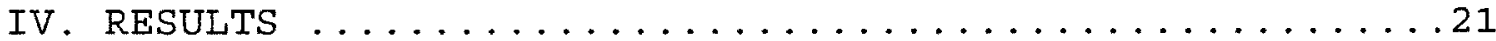

Overview of Total Sample's Responses ............21

Areas of Worry Reported by the Total Sample and by

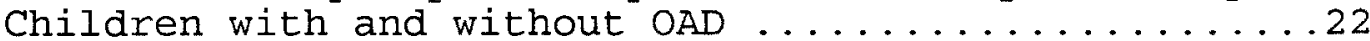

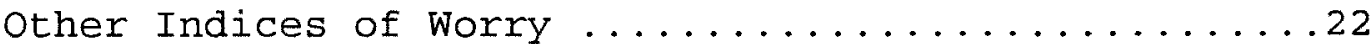

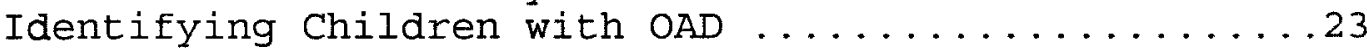

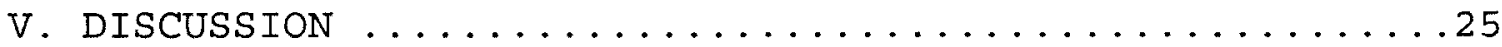

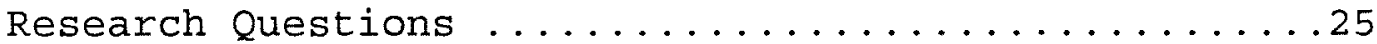

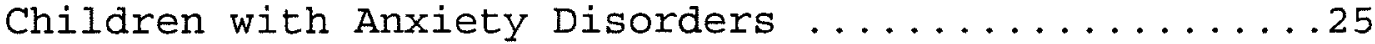

Worry, Anxiety, and their Relation ...........28

Identifying Children with $\mathrm{OAD} \ldots \ldots \ldots \ldots \ldots \ldots$

Limitations and Future Directions .............31

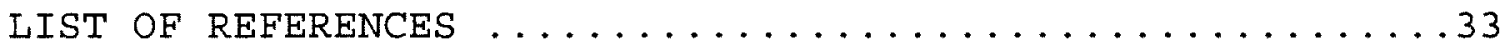




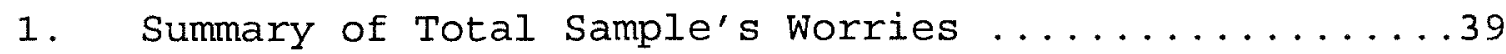

2. Specific Types of Worry Reported by Total sample ...40

3. Summary of Worries: Children without OAD .......42

4. Summary of Worries : Children with OAD .........43

5. Specific Types of Worry Reported by Children with

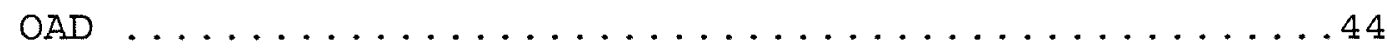

6. Specific Types of Worry Reported by Children without

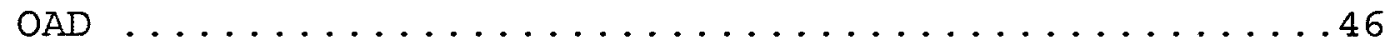




\section{LIST OF FIGURES}

FIGURE

PAGE

1. Age, Severity, and Children's Worries .........48

2. Age and Number of Children's Worries ...........49

3. Worry and the Effects of Age and Gender .........50

4. Worry Reported by Children with and without $O A D$ During Childhood or Adolescence .............51

5. Areas of Worry Reported by Children with and without OAD During Childhood or Adolescence ............52 


\section{Chapter 1}

Introduction

Worry, everyone does at one time or another, especially during childhood and early adolescence, when persons are least experienced in life. The American Heritage Dictionary describes worry as, "to feel uneasy about some uncertain or threatening matter, .... mental uneasiness or anxiety." Ingram (1990) described worry as, "as an awareness of selfreferent, internally generated information that stands in contrast to an awareness of externally generated information." However one describes worry, its significance and role in the development/maintenance of childhood pathology merits examination.

In the field of psychology, worry is sometimes thought of as being part of a survival mechanism (Mathews, 1990). Its task is the evaluation of possible outcomes, based on current and hypothetical situations, that persons view as threatening. These threats need not be based in reality, but may instead reside in the perceptions of danger. In addition, the process of worry is often experienced as being intrusive and automatic; for instance, when one is faced with giving an oral presentation. Worry, when activated, allows a person to think of all the possible things that could go wrong (e.g., dropping your papers or losing your place during a public reading), and the way in which those things could be corrected or avoided. Put simply, the 
functional potential of worry is that of problem solving or trouble shooting.

For the objectives of this research, worry and anxiety will be viewed in the following context. Worry will be described as being a single subsystem of a larger operation - anxiety (Barlow, 1988; Borkovec, Shadick, \& Hopkins, 1991). Anxiety, more specifically, is defined as an intense state of "affective, behavioral, physiological, and cognitive" readiness to respond to actual or perceived threat (Lang, 1977: Marks, 1969; Rachman \& Hodgson, 1974; Silverman, La Greca, \& Wasserstein, 1995). 
Chapter 2

Literature Review

Theoretical Issues

Children's worries are of particular theoretical importance for several reasons. Research has indicated that persons suffering from many psychological disorders, most notably anxiety disorders, have an information processing bias which distorts their perceptions (Ingram, 1990; Kendal1, Howard, \& Epps, 1988; Mathews \& MacLeod, 1985). These individuals tend to have a heightened sense of selffocused attention (Buss, 1980; Carver \& Scheier, 1986; Sarason, 1986). That is, they give greater importance to self-generated information than to data which they gather from external sources. This heightened sense of self-focus serves to intensify the experience of anxiety-provoking information, causing greater arousal as well as increased feelings of anxiety, depression and hostility (Gibbons, Smith, Ingram, Pearce, Brehm, \& Schroeder, 1985).

Furthermore, these individuals tend to think more (i.e., worry) about stimuli that they find anxiety-provoking (Carver, Peterson, Follansbee, \& Scheier, 1983;

Deffenbacher, 1978; Marlett \& Watson, 1968).

Theoretically, worry may also act to inhibit the processing of anxiety-producing material (Foa \& Kozak, 1986). When Borkovec and $\mathrm{Hu}$ (1990) exposed speech-anxious adults to fear-provoking situations, they experienced significantly greater levels of fear and lower levels of 
habituation than non-worried speech-anxious adults. Although these findings cannot be viewed as conclusive in their application with children, they do suggest implications for treatment.

This distortion process has been represented as influencing cognitive structure, cognitive propositions, cognitive operation, and cognitive product (Kendall et al., 1988). Distortions in cognitive structure make reference to the manner in which information has been organized in memory. Memories that are worry-related are thought to be organized in such a way that they are more obtainable (Eysenck, 1984). Distortions in cognitive propositions are over-representations of worry-related information in memory. Distortions in operation refer to misrepresentations in the processing of information. These distortions may take place as a result of a heightened awareness of worry relatedinformation (Mathews \& Colin, 1985; Mathews, 1990), an amplification of worry stimuli as information is processed into memory, or an amplification of worry-related information as it is recalled. Finally, distortions in cognitive product take place as a result of the value that information is given (i.e., attribution).

\section{Clinical Issues}

Clinically, worries are of particular importance in childhood and adolescent anxiety disorders. Excessive worry is the hallmark feature of a number of such disorders, including, Separation Anxiety Disorder and Overanxious 
Disorder. These disorders are of particular importance due to their high prevalence among children (Anderson, Williams, McGee, \& Silva, 1987; Beidel, 1991). Overanxious disorder, notably, being the most commonly reported psychiatric diagnosis assigned to children (Kashani et al., 1987; Kashani \& Orvaschel, 1988; McGee et al., 1990).

The worry, for instance, experienced by children who suffer from Overanxious Disorder centers around future occurrences such as tests, social gatherings, and competitive events (i.e., sports). Their worry is excessive or unrealistic in nature, involving questions of competence and/or apprehensions of being judged by others. These worries commonly focus on future events; they may, however, also revolve around past incidents and are ruminative in nature. In contrast to other anxiety disorders, children who suffer from Overanxious Disorder experience worries that cover a much broader range and greater severity.

DSM-III-R provided a general description of the kinds of worry experienced by children diagnosed with anxiety disorders. However, no published research is available on the frequency, intensity, number, and nature of this worry in a clinic sample of children, although silverman and Colleagues (1995) recently reported for a non-clinic sample. It would be useful to obtain similar information for a nonclinical sample for comparative purposes. This would help to increase current knowledge about worry in childhood, as 
well as help to obtain a better picture of how worry functions in "clinical" anxiety.

Because of the dearth information available about clinical worry, there are no established criteria to determine the significance of worry in pathology. This poses special problems for researchers, in light of the common occurrence of clinical levels of anxiety in nonclinical children (Bell-Dolan, Last, \& Strauss, 1990). This leaves many important questions unanswered. For instance, to what extent does "excessive worry" indicate dysfunctional process (Vasey, 1993), and when is worry clinically meaningful. In addition, little information is available on whether the types of worries experienced by specific anxiety disorders in children (e.g., Overanxious Disorder, Social Phobia, Simple Phobia, etc.) differ in terms of quality and quantity.

Further, little research has been conducted that examines the basic link between worry and anxiety in a child clinical population. Of a number of adult studies (Borkovec, Robinson, Pruzinsky, \& DePree, 1983; Wisocki, 1988; Tallis, 1989), Tallis (1989) most clearly illustrates that clinically anxious adults worry more than non-anxious adults. Similarly, Silverman et al. (1995) found that in a sample of non-diagnosed children (i.e., school children), high anxious children experienced greater worry than low anxious children. However, no research is currently available which examines the link between anxiety and worry 
in a clinical sample of children. For instance, in light of the current literature on anxiety, the worries of children with overanxious disorder would be expected differ from the worry of children diagnosed with other types of anxiety disorders. More specifically, children with Overanxious Disorder would be expected to have a greater quantity, intensity, and frequency in occurrence of worry than children with other anxiety disorders.

\section{Developmental Issues}

There have been several studies that have explored the nature of children's worries (Jersild, Goldman, \& Loftus, 1941; Pintner \& Lev, 1940; McNally, 1950; Silverman et al., 1995; Simon \& Ward, 1974). Pintner and Lev (1940) were among the first to be interested in the worries of children. They examined the types of worry that children experienced and the importance that children placed on their worries. In addition, they made gender and socio-economic comparisons to determine their effects on children's worries.

Pintner and Lev (1940) recruited fifth and sixth grade students to complete a worry questionnaire. In total, 540 students, half of whom were female, completed the questionnaire. These children were part of the New York City School system. They responded to 53 questions by indicating that they never, sometimes, or often experienced a particular worry.

Results revealed that children were most concerned about failing tests; the second greatest concern was their 
mother working too hard; and the third greatest concern was their mother getting sick. Children were least concerned about what the authors described as "imaginary or unreasonable" worries such as getting robbed. When responses were analyzed categorically, children worried most about their families, followed by school, personal adequacy, social adequacy, economic, health, imaginary and ornamental concerns. The data also indicated gender differences. Male subjects were found to worry more about their personal and social adequacy, as well as economic concerns, than did their female counterparts. Finally, socio-economic status was considered in evaluating the data. Children of lower socio-economic status were found to experience more worry economic concerns than children of higher socio-economic status.

In a subsequent study using similar methodology, Pintner and Lev (1940) and Jersild et al. (1941) examined the worries experienced by children. Like Pintner and Lev (1940), Jersild et al. (1941) examined the types of worries that children experienced and how frequently they occurred. In addition, Jersild et al. (1941) examined the effects of different school programs on children's worries.

Jersild et al. (1941) administered a worry inventory to 1124 (i.e., 594 male and 530 female) fifth and sixth grade students. Five hundred sixty nine of these children were from progressive schools, whereas 555 students were from conventional schools. The subjects represented fifth and 
sixth grade classes -- one each from 16 elementary schools in New York City. The researchers described progressive schools as those that allowed children greater freedom to pursue their own interests, to work independently, and to express themselves.

The authors compared the worries reported by children in conventional and progressive (i.e., new theory based) schools using a paper and pencil instrument. This worry inventory was composed of 25 items, some of which were taken from Pintner and Lev's (1940) worry inventory.

Questionnaire items fell into one of two primary areas, school related fears and non-school related fears. Subjects responded to questions indicating that they experienced a particular worry sometimes, often, or never.

Jersild et al. (1941) found no substantial differences in the worries reported by children in conventional and progressive schools. When comparisons were made between male and female children, few important differences were noted. Female children tended to worry more about being followed by strangers; boys tended to worry more about being physically struck. In general, female children tended to worry more than male children.

The findings of Jersild et al. (1941) were similar to those of Pintner and Lev (1940). They found that children worried most about failing tests and other occurrences that they had previously experienced in life, or worries that could be described as reality based. In comparison, 
children reported worrying least about items that concerned ghosts, being kidnapped, etc.; items the authors described as imaginary or unreasonable.

Differences in the findings of Jersild et al. (1941) and those of Pintner and Lev (1940), might be due to differences in the number of questions contained in their worry inventories (i.e., Jersild, Goldman, and Loftus, 25 questions; Pintner and Lev, 53 questions). The Jersild, et al. (1941) worry inventory, due to its shorter length, did not tap into as many areas of worry as Pintner and Lev's (1940) worry inventory. For instance, Pintner and Lev (1940) questioned children about their concerns for their parents (i.e., "mother getting sick" or "mother working to hard"). In contrast, children in the Jersild et al. (1940) were only asked about their fear of being scolded. Children in the Jersild et al. (1941) study may have been just as concerned about their mothers becoming sick as the children in the other sample, but were not presented with the opportunity to relate that information.

Simon and Ward (1957) furthered the work of earlier research in the area of children's worries. Like previous researchers, they used measures that identified children's worries and the frequency with which children experienced their worries. However, Simon and Ward (1941) also gauged the intensity of children's worries. In addition, they used pilot studies to develop their questionnaires. This procedure thereby increased the accuracy and validity of 
their findings. Six-hundred seventy-two subjects, 336 from grammar schools and 336 secondary modern schools, participated in the study. Subjects ranged in age from 12 years, 2 months to 14 years, 11 months. These subjects completed two questionnaires.

Children indicated on one questionnaire the worries that they experienced and how often they experienced those worries. On the second questionnaire, children indicated the worries that they experienced and the intensity of those worries. Subjects completed these questionnaires in groups of 25 to 30 children. All students responded to both questionnaires twice, first during an initial test administration and second, three weeks later, in a follow-up test administration.

Analysis of the questionnaire responses indicated that older children reported a larger variety of worries than younger children. Younger children, however, reported more frequent and more intense worries than older children. In particular, grammar school children worried more about economic and school matters than secondary modern school students. Secondary modern school students, in contrast, worried more about health and imaginary concerns than grammar school students.

Most recently, Silverman et al. (1995) examined the worries of children. A primary goal of their study was to examine if the worries children reported experiencing had significantly changed over the past fifty years. For 
instance, worries that researchers in the past might have viewed unreasonable, or unrealistic (e.g., kidnapping or robbery), and which were seldom reported in 1940, might be reported more frequently by contemporary children. Second, they examined the "empirical relationship between children's worry and anxiety."

Subjects were 273 children (141 male and 132 female), who ranged in age from 7 years, 8 months, to 12 years, 9 months. Most of these children attended a public school in a large metropolitan area. The sample consisted of second, third, fourth, fifth, and sixth graders -- two classes of each. Ethnically, the sample was composed of middle-class White, Asian, Hispanic, and African American children. Subjects were individually administered a semistructured interview. During the interview, children were questioned as to the worries that they experienced, the intensity and frequency thereof (i.e., how often and how many times a day). In addition, children completed several child self-report measures (i.e., the Revised Children's Manifest Anxiety Scale, the Test Anxiety Scale for Children, the Social Anxiety Scale for Children-Revised, and the Childhood Anxiety Sensitivity Index) in their classroom.

Results revealed that these children worried most about health, school, and personal harm. Health concerns ranged from others (e.g., parents) becoming ill to personally contracting AIDS. School-related worries mainly revolved around failing tests, whereas personal harm represented 
children's fears of being robbed, shot, or stabbed. In particular, fear of personal attack was the most common individual item selected by children.

Ethnic, gender, and age differences were also found for the sample. African American children reported experiencing a greater number of worries than white or Hispanic children. In gender comparison, female subjects reported more worries than male subjects, with the exception of African American females who did not differ significantly from African American males. More specifically, African American children reported a greater number of worries concerning personal harm and family than white or Hispanic children, while both African American and Hispanic children reported a greater number of health concerns than white children. African American subjects also reported more intense worry related to family than either white or Hispanic subjects. In addition, younger children exhibited a greater intensity of concern than older children.

When children with high and low anxiety levels of worry were compared, children with high anxiety levels reported a higher frequency of worry. They also experienced their worry as being more intense than children with low anxiety levels. In addition, children with high anxiety levels reported a significantly greater number of worries, as well as a greater number of areas of worry, than children with low anxiety levels. Based on these findings, the authors examined criteria with which to identify high and low 
anxious children (i.e., number of worries $\geq 8$ and intensity of worries $>2$ ). With this criteria, the authors found that they could properly identify $93.8 \%$ of high anxious children. The work of Silverman et al. (1995) is important for several reasons. First, it provides current normative information on worries in a contemporary cohort. This information gives continuity to previous research, allowing researchers to trace changes in the worries that children experience. Second, the use of a semi-structured instrument allowed greater sensitivity to children's worries than previous methods. Children were able to express worries which earlier methods could not detect, as well as worries that may not have existed when earlier research was conducted (e.g., AIDS, homelessness, drug addiction, school shootings, etc.). Third, ethnic differences were examined. This was the first study to evaluate the effects of ethnicity on how children experienced worries (e.g., frequency, intensity, etc.). Fourth, and perhaps most relevant to this research proposal, links between anxiety and worry were established. Initial standards were suggested that may be employed as a starting point for future research, to help determine how worry might be used to use to differentiate "clinically" meaningful worry from non-clinically meaningful worry. Specifically, Silverman et al. (1995) proposed that children who experienced eight or more worries $(\geq 8)$, and rated those worries as having an 
intensity greater than two $(>2)$, could be identified as high anxious children.

\section{Purpose}

The first goal of this study was to examine the worries reported by a clinic sample of children diagnosed with anxiety disorders. At present, no published research is available on the frequency, intensity, number, and areas of worries experienced by these children.

The second goal of this study was to further establish the link between worry and anxiety. To accomplish this, a comparison of the worries experienced by children with Overanxious Disorder (i.e., characterized by excessive worry) and children with other anxiety disorders (i.e., characterized by less worry) was made. It was expected that children with Overanxious Disorder would report a greater number of worries, greater number of areas of worries, greater intensity of worries, and a greater frequency in occurrence of worries, than children with other types of anxiety disorders.

The final goal of this study was to explore, in a preliminary way, the utility and generalizability of the criterion set forth by Silverman et al. (1995). As noted, Silverman et al. (1995) proposed that children who experienced eight or more worries $(\geq 8)$, and rated those worries as having an intensity greater than two (> 2), could be identified as high anxious children. Thus, the utility of this criterion with a sample of children diagnosed with 
Overanxious Disorder was explored, and adjusted accordingly to improve overall sensitivity and specificity in the classification of $O A D$. 


\section{Chapter 3}

Method

\section{$\underline{\text { Subjects }}$}

Subjects were 59 children, 32 male and 27 female, who were diagnosed with DSM-III-R anxiety disorders. Thirty three of the children were diagnosed with OAD. Of the 26 children without $O A D, 20$ were primarily diagnosed with a Simple Phobia; 4 were primarily diagnosed with Separation Anxiety Disorder, and 2 were primarily diagnosed with Social Phobia. They ranged from six to sixteen years in age, with a mean age of nine years, ten months. The mean age for male children was ten years and for female children, nine years, six months. The sample was primarily composed of white and Hispanic children.

All children and their parents presented to the Child Anxiety and Phobia Program housed within the Child and Family Psychosocial Research Center at Florida International University, Miami, Florida. All children were diagnosed with one or more anxiety disorders such as Overanxious Disorder, Social Phobia, Simple Phobias, etc. Although they may have presented with other types of problems (e.g., Attention Deficit Hyperactivity Disorder), their primary problem was that of anxiety or phobic disorders.

Most children were referred to the Center by school counselors, teachers, or other mental health professionals. However, a number of the children were self-referrals. 
Self-referrals were most commonly recruited through advertisement placed in school and local news papers.

Initial contact with all potential subjects typically occur by phone. Parents usually called the Center and were administered a brief phone screen. The phone screen served two primary purposes. The first was to gather initial information needed to determine if the child was appropriate for further assessment at program (i.e., was the child's pathology anxiety related). The second was to give the parent and child information about the research clinic and to prepare them for the assessment procedures.

\section{Procedure}

The assessment procedure took place during two session. During the first session, prior to testing, interviewers explained the assessment procedures, client confidentiality, and review consent forms with the parent and child. After completing this introductory phase of the assessment, the parent was asked to return to the waiting room and complete a battery of questionnaires while the child's assessment interview was conducted. The interviewer administered the Anxiety Disorders Interview Schedule for Children - Child Version (ADIS-C) to the child at this time. After completing the child's interview, the child was taken to a waiting room to complete a battery of questionnaires while the parent was administered the Anxiety Disorders Interview Schedule for Children - Parent Version (ADIS-P). At the end of the first assessment session, an appointment was set for 
the parent and child to return the following week for the second assessment session.

During the second session, the interviewer administered the worry inventory to the child, and the remaining measures that comprise the standard assessment battery. At the completion of the child battery, the parent was administered the remaining measures of the standard battery. Assessment of Childhood Worry

Training of Interviewers. Interviewers for this study were either Dr. Silverman, female graduate students, or a post doctorate fellow. Each interviewer, prior to working with actual subjects, received extensive group and individual training, directed by Dr. Silverman.

Description of Interviews. The Anxiety Disorder Interview Schedule for Children (ADIS-C and ADIS-P) was used to ascertain DSM-III-R diagnoses of anxiety disorder/s in the child participants in this study. The ADIS-C and ADIS-P were developed based on the ADIS (DiNardo, O'Brien, Barlow, Waddell, \& Blanchard, 1983). The ADIS-C and ADIS-D allowed the clinical-researcher to assess for a broad range of childhood disorders. The interviews were designed for the clinical research setting and take approximately one hour to administer. Diagnoses were based on a composite derived from the child and parent ADIS interviews. Test-retest and interrater reliability for the ADIS-C and ADIS-P have been found to be satisfactory (Silverman \& Eisen, 1992; Silverman \& Nelles, 1988; Silverman \& Rabian, in press). 
The same interviewing procedures used by Silverman et al. (1994) to assess childhood worry were used in this study. Specifically, the interview was designed to assess children's worries in fourteen common areas (i.e., school, Performance, Classmates, Friends, War, Disasters, Money, Health, Future Events, Personal Harm, "Little Things," Appearance, Family) as well as "other worries" (i.e., worries that do not fall into the other categories). Children were asked for each area, do you worry about it (e.g., "Do you worry about disasters?"). If a child indicated that $\mathrm{s} / \mathrm{he}$ experienced worry in that area, $\mathrm{s} / \mathrm{he}$ was asked what he specifically worried about (e.g., "What specifically is it about disasters that you worry about?"). Each child's responses were transcribed literally for later scoring. If a child reported experiencing no worry in a particular area, the interviewer proceeded to the next area of inquiry.

When a child reported experiencing a worry in a particular area, the interviewer asked them to indicate the intensity of the worry on a five-point scale $(0=$ none, $1=$ a little bit, 2 = some, 3 = a lot, 4 = very, very much). Children were also asked to indicate the frequency of the worry $(0=$ none, $1=$ some, $2=a$ lot $)$. To help children rate their worries, a visual aid (i.e., "worry thermometer") was used during the interview.

Children's responses to the fourteen general queries were further categorized into 41 sub-division. These 
categories were originally devised based on subjects' verbatim responses to enable more qualitative evaluations of responses. Interrater reliabilities for these categories ranged from .80 to .90 (Silverman, et al., 1995). 
Chapter 4

Results

Overview of Total Sample's Responses

Children, on average, reported experiencing 6.64 worries ( $S D=5.25$; range from 1 to 22 ) when interviewed. These worries bridged 4.61 (SD $=2.77$; range from 1 to 11 ) of 14 areas. In Table 1 and Table 2 more specific information is given on the number, rank, and areas of worry reported by the total sample (see Table 1 and 2).

Analysis of Variance were used to evaluate the total sample's age, gender, and ethnic responses. Although no main effects were found for gender and ethnicity, two main effects were obtained for age. First, as children increased in age, they tended to report decreased severity in worry ( $F[9,44]=2.973, \mathrm{p}<.008$; see figure 1); second, they tended to report an increase in the number of worries ( $F[9,40]=49.774, \mathrm{p}<.017$; see figure 2 ).

A two-way interaction was found for age and gender $(F[7,40]=2.671, p<.023$; see figure 3). As boys increased in age, they tended to report a greater number of worries. In contrast, girls tended to report slightly fewer worries as they increased in age. It should be noted, however, that girls reported a greater number of worries than boys for each age (i.e., 6 to 16). Categorically, girls experienced significantly more worry than boys in the areas of future events, little things, and family ( $p<.039)$. 
Areas of Worry Reported by the Total Sample and by

Children with and without $O A D$

The three most common areas of worry reported by the total sample of children were Health, School, and Disasters (See Table 1.). Health worries included: someone else's health, getting sick, bodily symptoms (e.g., nausea), going for medical care, dying, operations/surgery, and getting AIDS (See Table 2). School worries consisted of concerns relating to performance (e.g., testing), being called on in class, and teachers. Disaster related worries primarily focused on hurricanes, floods, and tornados. Furthermore, the areas of Health and School worry received the greatest number of responses from children.

The three most common areas of worry reported by children without $O A D$ were School, Disaster, and Health (See Table 3). In contrast, children with OAD most commonly endorsed Health, School, and Future Events (See Table 4). Future Events refers to worries which were: family related, school related (e.g., starting school), medical (e.g., seeing a doctor), or general (See Table 5). In addition, children without $O A D$ gave the greatest number of responses to the areas of School, Health, and Disasters, while children with OAD gave the greatest number of responses to the areas of Health, School, and Future Events.

\section{Other Indices of Worry}

Analysis of Variance was used to compare the responses of children with $O A D$ to children without OAD across four 
indices of worry: (1) total number of worries, (2) areas of worry, (3) intensity of worry, and (4) frequency/event of worry. For total number of worries, a main effect was found $(F[1,52]=10.128, p<.002)$. Children with OAD reported experiencing a greater number of worries (mean=8.64) than children who were diagnosed without $\mathrm{OAD}$ (mean=4.12). A similar effect was also obtained for the number of areas of worry $(F[1,52]=8.600 ; p<.005)$, children with OAD reported experiencing worries in a greater number of areas (mean=5.58) than children without $O A D$ (mean=3.38). NO significant differences were found for intensity or Erequency/event of worry.

An interaction was obtained for type of disorder and age $(F[1,50]=6.656, p<.013)$. When subjects' responses were compared between two age groups (i.e., children 6-11 versus adolescents 12-16), younger children with $O A D$ reported significantly less worry then older children with OAD (see figure 4). In contrast, younger children without OAD tended to report a slightly higher number of worries than older children without $O A D$. A similar relationship for disorder and age groups was obtained for the number of areas in which children responded $(F[1,50]=8.814, p<.005$; see figure 5). Identifying Children with $O A D$

In light of the severity of anxiety generally associated with $O A D$, it was expected that children with $O A D$ would be discernable from children without $O A D$ based on the worry that they reported. Analysis of the data indicated 
that the two groups (i.e., children with $O A D$ and children without $O A D)$ differed significantly in two primary areas: the number of worries reported by children and the number of areas in which children reported worry. Using five or more areas of worry as a cut-off score, $66^{\circ}$ of children in the sample were properly identified. Using seven or more worries as a cut-off score, $69 \%$ of children in the sample was properly identified. When areas of worry and numbers of worries were combined to form a cut-off scores, proper identification was not increased. If severity was considered, in addition to the number of areas of worry and the number of worries, proper identification was further increased. By using seven worries, and a minimum of three areas of worry or a severity of two or greater, $75 \%$ of subjects could be properly identified. For this criterion, a sensitivity (i.e., number of person with $O A D$ who were correctly identified) of $58 \%$ was obtained with a specificity (i.e., number of person correctly identified as having an other anxiety disorder) of $96 \%$. Although this criterion was not exceptionally accurate in identifying person with $O A D$, it was highly effective in ruling-out $O A D$ as a co-diagnosis when children were diagnosed with other anxiety disorders. 
Chapter 5

Discussion

$\underline{\text { Research Questions }}$

There were several objectives of this study. First, this study examined the worries reported by a sample of children diagnosed with anxiety disorders. Second, it attempted to further establish the link between worry and anxiety. Third, it explored, in a preliminary way, the utility and generalizability of worry as criterion for differentiating anxiety disorders.

\section{Children with Anxiety Disorders}

The first goal of this study is of particular interest. During the past 50 years a number of studies have examined the worries of school age children, most recently Silverman, et al. (1995). However, at present, no published research is available on the frequency, intensity, number, and areas of worries experienced by a clinical sample of children with anxiety disorders.

Taken as a whole, the responses of the total sample of children with anxiety disorders, in general, were very similar to those of a non-clinic sample of children (Silverman et al., 1995). For instance, both samples of children reported the highest number of worries in the areas of Health, School, and Personal Harm. A similar pattern of responses was also obtained for the most common areas of worry reported by the samples. 
Children in both samples also reported Health, followed by school as their most common areas of worry. However, the two samples differed in their third most common areas of worry (i.e., clinical sample - Disasters; non-clinical sample - Personal Harm); this may have been due to the time frame in which the data were collected. A good portion of the data collected from children in the clinic sample was gathered shortly after the occurrence of Hurricane Andrew.

The high number of children who reported health concerns in this clinic sample of children were also consistent with earlier research (Silverman et al., 1995). These worries were quite diverse, for instance: someone else's health, getting sick, bodily symptoms (e.g., nausea), going for medical care, dying, operations/surgery, and getting AIDS (See Table 2). This emphasis on health concern among children seems consistent with an increased public awareness of health related issues (e.g., the debate over universal health coverage, Aids public awareness campaigns, and the increased prevalence of Aids related death).

School worry reported by the children in this study was primarily comprised of traditional types of concerns. For instance, children's specific worries about school generally fell into the areas of performance, being called on in class, and teachers. In addition, the frequency and severity levels reported by these children (see Table 1) were similar to those of the non-clinical sample of children of Silverman et al. (1995). 
In the area of Personal Harm, the children's responses in this study were also highly similar to the responses of Silverman et al. sample. Specifically, although the clinic sample in this study did not report worries about personal safety as commonly as the non-clinic sample of Silverman et al., the clinic sample did report highest severity of worry in the general area of Personal Harm. In addition, like non-clinic children, clinic children had similar pattern of endorsement for the area of Personal Harm (i.e., number of worries reported).

With respect to age, gender, and ethnic responses for the total sample, two main effects were observed for age. First, as children with anxiety disorders increased in age, they tended to report a less severe worry; second, they tended to report more worry with age. These finding were consistent with earlier research (Silverman et al., 1995; Simon \& Ward, 1957). Although there was no significant main effect for ethnicity or gender, there was a tendency for female children to report a greater number of worries and a greater number of areas of worry than male children.

An interaction was found for age and gender. As male children increased in age, they tended to report more worry; female children reported slightly less worry as they increased in age. This appears to contradict earlier finding on initial examination (Silverman et al., 1995).

A conclusive explanation for the interaction obtained for age and gender in this study is not possible. This was 
the first study undertaken that examined the worry reported by a clinic sample of children. Although other studies have examined the worries of non-clinic children, similar interactions have not been found. There are, however, a number of possible explanations for its occurrence. One of the more likely explanation for the interaction obtained between age and gender was the different rates that male and female children mature. Female children tend to mature early than male children, and as a consequence be more realistic about all the things to "worry about." Therefore, only as male children became older, and they to became more realistic, the number of worries that they reported became increasingly similar those of female children.

Worry, Anxiety, and their Relation

The second goal of this study was to further establish the link between worry and anxiety. To accomplish this, a comparison of the worries experienced by children with Overanxious Disorder (i.e., characterized by excessive worry) and children without $O A D$ (i.e., characterized by less worry) was undertaken. It was expected that children with Overanxious Disorder would report a greater number of worries, greater intensity of worry, and a greater frequency in occurrence of worries, than children without $O A D$. Differences in children's responses were examined for four indices of worry: total number of worries, areas of worry, intensity of worry, and frequency/event of worry. 
As anticipated, children with $O A D$ and children without $O A D$ differed significantly in several manners. First, in the total number of worries reported by children. Children with OAD reported experiencing a greater number of worries (mean=8.64) than children who were diagnosed with other anxiety disorders (mean=4.12). A similar effect was also obtained for the number of areas of worry, children with OAD reported experiencing worries in a greater number of areas (mean=5.58) than children without OAD (mean=3.38).

These findings offer additional evidence of the link. between anxiety and worry. That is, they suggest that certain types of anxiety disorders, specifically OAD, are indeed characterized by more excessive worry than other types of anxiety disorders. This notion is presumed in the DSM III-R, but in fact, it has never been confirmed in any manner, empirically. This study is the first to provide evidence for this notion. Interestingly, the children without $O A D$ versus children with $O A D$ did not differ from each other in terms of severity or frequency. Perhaps this was because of a potential ceiling effect. That is, all the children participating in this study were clinic-referred and generally all exhibit high severity in their anxiety symptomatology. Thus, all the participants worry, and they all appear to do so with high severity. As noted, the distinction appears more in terms of number of worries and number of areas of worries. Future research should determine whether severity of worries (and 
frequency/occurance) is a more sensitive indicator with other types of population.

Identify Children with $O A D$

The third goal of this study was to explore in a preliminary way the utility and generalizability of the criterion set forth by Silverman et al. (1995). Silverman et al. (1995) proposed that based on the number and intensity worries experienced by a child, children could be identified as being a high or low anxious child. These criteria were examined to see if they can be used to differentiate children with $O A D$ from children without $O A D$ (e.g., simple phobias). To evaluate the effectiveness of this strategy, sensitivity and specificity were calculated based on the worry reported by children in the sample.

Analysis of the data indicated that children with $O A D$ and children without $O A D$ could be differentiated by using severity and the number of worry reported by children, not as effectively as Silverman et al. (1995). That is, by using severity and the number of worries reported by children, only $66 \%$ of children in the sample were properly identified as having $O A D$ or having another type of anxiety disorders. If instead however, seven worries and a minimum of three areas of worry or a severity of two or greater were used, $75 \%$ of subjects could be properly identified. This criterion produced a sensitivity (i.e., number of person with $O A D$ who were correctly identified) of $58 \%$ was obtained 
with a specificity (i.e., number of person correctly identified as having an other anxiety disorder) of $96 \%$.

Thus, although this criterion was not exceptionally accurate in identifying person with $O A D$, it was highly effective in ruling-out $O A D$ as a co-diagnosis when children were diagnosed with other anxiety disorders. Moreover, the use of the number of categories as an additional criterion appeared to improve proper identification of children's anxiety disorders groups for several reasons. First, it gives an additional measure of severity. This allows for a more complete picture of a anxiety experienced by a child. Second, it helps to mediate the effects of averaging on severity ratings. For instance, a child who experienced seven worries (severity scores of: $4,3,2,1,1,1,1 / 7=$ 1.86) might obtain lower severity scores than a child who experienced only two worries (severity scores of: $2,2 / 2=$ 2).

\section{Limitations and Future Directions}

Although this study represents an important contribution in that it is the first to document the worries of a clinic sample of children with anxiety disorders, there are several limitations that are worth noting. First, it is uncertain whether these findings are generalizable to other clinic samples of children with anxiety disorders.

Replication in other settings would therefore be important. second, although this study found that worry was linked to anxiety, no measures such as, the Child self-Rating scales, 
Third, this study relied only on the use of the children as the informants. Although greater worry was associated more with children with $O A D$ than with children without OAD, quantitative relationships between worry and other anxiety indices (e.g., Self-Rating Scales) remain unexplored. Granted, children are the "informants of choice," when it comes to assessing internalizing states, however, valuable information may be lost when only one source of information is drawn upon (Silverman \& Eisen, 1992; Silverman et al., 1995). Thus, it will be important to extend the present study's methodology by obtaining information from multiple sources (e.g., parents). Finally, research needs to be undertaken in which the worries of children who meet different DSM-IV anxiety disorders are compared. For instance, how does the worry experienced by children with OAD differ from the worry experienced by children with Social Phobia.

In closing, this study is important in further showing how worry and anxiety are related in children. It provided evidence of the generalizability and utility of worry in differentiating children's anxiety disorders. It was the first study to offer empirical evidence for the DSM III-R association of $O A D$ with excessive worry, and the first study to examine the relation of worry and anxiety in a clinic sample of children with anxiety disorders. It thus represents an important extension of previous research in this area. 


\section{Reference}

American Psychiatric Association (1987). Diagnostic and Statistical Manual of Mental Disorders, 3rd edition, (DSM-III-R). Washington, DC: American Psychiatric Association.

Anderson, J. C., Williams, S. M., McGee, R., and Silva, P. A. (1987). DSM-III disorders in preadolescent children: prevalence in a large sample from the general population. Archives of General Psychiatry, 44, 69-76.

Barlow, D. H. (1988). Anxiety and its disorders: the nature and treatment of anxiety and panic. NY: Guilford Press.

Beidel, D. C. (1991). Social phobia and overanxious disorder in school-age children. Journal of the American Academy of Child and Adolescent Psychiatry, 30, 545-552. Bell-Dolan, D. J., Last, C. G., and Strauss, C. C. (1990). Symptoms of anxiety disorders in normal children. Journal of the American Academy of Child and Adolescent Psychiatry, 29, 759-765.

Borkovec, T. D. and Hu, S. (1990). The effect of worry on cardiovascular response to phobic imagery. Behavior Research and Therapy, 28, 69-73.

Borkovec, T. D., Robinson, E., Pruzinsky, T., and DePree, J. A. (1983). Preliminary exploration of worry: some characteristics and processes. Behavior Research and Therapy, 21, 9-16. 
Borkovec, T. D., Shadick, R., and Hopkins, M. (1991). The nature of normal worry and pathological worry. In R. M. Rapee and D. H. Barlow (Eds.), Chronic anxiety: generalized anxiety disorder and mixed anxiety-depression (pp. 29-51). NY: Guilford Press.

Buss, A. (1980). Self-consciousness and social anxiety.

San Francisco: W. H. Freeman.

Carver, C. S., Peterson, L. M., Follansbee, D. J., and Scheier, M. F. (1983). Effects of self-directed attention on performance and persistence among persons high and low in test anxiety. Cognitive Therapy and Research, I, 333-354.

Carver, C. S., and Scheier, M. F. (1986). Functional and dysfunctional responses to anxiety: the interaction between expectancies and self-focused attention. In $R$. Schwarzer (Ed)., Self-related cognitions in anxiety and motivation (pp. 111-141). Hillsdale, NJ: Erlbaum. Deffenbacher, J. L. (1978). Worry, emotionality, and taskgenerated interference in test anxiety; an empirical test of attentional theory. Journal of Educational Psychology, 70, 248-254.

DiNardo, P. A., O’Brien, G. T., Barlow, D. H., Waddell, M. T., and Blanchard, E. B. (1983). Reliability of DSM-III anxiety disorder categories using a new structured interview. Archives of General Psychiatry, 40, 10701079 . 
Eysenck, M. W. (1984). Anxiety and the worry process. Bulletin of the Psychonomic Society, 22, 545-548.

Foa, E. B., and Kozak, M. (1986). Emotional processing of fear: exposure to corrective information. Psychological Bulletin, 99, 20-35.

Gibbons, F. X., Smith, T. W., Ingram, R. E., Pearce, K., Brehm, S. S., and Schroeder, D. J. (1985). Selfawareness and self-confrontation: effects of self-focused attention on members of a clinical population. Journal of Personality and social Psychology, 78, 662-675.

Ingram, R. E. (1990). Self-focused attention in clinical disorders: review and a conceptual model. Psychological Bulletin, 107, 156-176.

Jersild, A. T., Goldman, B., and Loftus, J. J. (1941). A comparative study of the worries of children in two school situations. Journal of experimental education, 9, $323-326$.

Kashani, J. H., Beck, N. C., Hoeper, E. W., Fallahi, C., Corcoran, C. M., McAllister, J. A., Rosenberg, T. K., and Reid, J. C. (1987). Psychiatric disorders in a community sample of adolescents. American Journal of Psychiatry, 144, 584-589.

Kashani, J. H., and Orvaschel, H. (1988). Anxiety disorders in mid-adolescence: a community sample. American Journal of Psychiatry, 145, 960-964. 
Kendall, P. C., Howard, B. L., and Epps, J. (1988). The anxious child: cognitive-behavioral treatment strategies. Behavior Modification, 12, 218-310.

Lang, P. J. (1977). Imagery in therapy: an information processing analysis of fear. Behavior Therapy, $8,862-$ 886 .

Marlett, N. J., and Watson, K. (1968). Test anxiety and immediate or delayed feedback in a test-like avoidance task. Journal of Personality and Social Psychology, $\underline{8}$, $200-203$.

Mathews, A. (1990). Why worry? The cognitive function of anxiety. Behavior Research and Therapy, 28, 455-468. Mathews, A., and Macleod, C. (1985). Selective processing of threat cues in anxiety states. Behavior Research and Therapy, 23, 563-569.

McGee, R., Feehan, M., Williams, S., and Partridge, F. (1990). DSM-III disorders in a large sample of adolescents. Journal of the American Academy of Child and Adolescent Psychiatry, 29, 611-619.

McNally, E. (1950). The worries of the younger pupils in scottish secondary schools. British Journal of educational Psychology, 21, 235-237.

Pintner, R., and Lev, J. (1940). Worries of school children. Journal of Genetic Psychology, 56, 67-76. Rachman, S. J., and Hodgson, R. S. (1974). Synchrony and desynchrony in fear and avoidance. Behavior research and Therapy, 12, 311-318. 
Sarason, I. G. (1986). Test anxiety, worry, and cognitive interference. In R. Schwarzer (Ed)., Self-related cognitions in anxiety and motivation (PP.19-33).

Hillsdale, NJ; Erlbaum.

Silverman, W. K., and Eisen, A. R. (1992). Age differences in the reliability of parent and child reports of child anxious symptomatology using a structured interview.

Journal of the American Academy of Child and Adolescent Psychiatry, 31, 117-124.

Silverman, W. K., La Greca, A. M., and Wasserstein, S. (1995). What do children worry about?: worries and their relation to anxiety. Child Development, 66, 671686.

Silverman, W. K., and Nelles, W. B. (1988). The anxiety disorders interview schedule for children. Journal of the American Academy of Child and Adolescent Psychiatry, 27, $772-778$.

Silverman, W. K., and Rabian, B. (1995). Test-retest reliability of the DSM-III-R childhood anxiety disorders symptoms using the anxiety disorders interview schedule for children. Journal of Anxiety Disorders, 9, 193-150. Simon, A. and Ward, L. O. (1974). Variables influencing the sources, frequency and intensity of worry in secondary school pupils. British Journal of Social and Clinical Psychology, 13, 391-396. 
Vasey, M. W. (1993). Development and cognition in childhood anxiety: the example of worry. In T. H. Ollendick and R. J. Prinz (Eds.), Advances in Clinical child psychology (Vol. 15) (pp. 1-39). NY: Plenum Press. Wisocki, P. A. (1988). Worry as a phenomenon relevant to the elderly. Behavior Therapy, 19, 369-379. 
Table 1

Summary of Total Sample's Worries

\begin{tabular}{|c|c|c|c|c|}
\hline Area & $\begin{array}{l}\text { No. of } \\
\text { Responses }\end{array}$ & $\begin{array}{l}\text { No. of } \\
\text { Children }\end{array}$ & $\begin{array}{l}\text { Intensity } \\
\text { of Worry }\end{array}$ & $\begin{array}{l}\text { Frequency/ } \\
\text { Event }^{\text {b }}\end{array}$ \\
\hline Health & 60 (1) & 33 (1) & $2.51(1.01)$ & $1.22(1.70)$ \\
\hline School & $53(2)$ & $32 \quad(2)$ & $2.54 \quad(1.00)$ & $1.72 \quad(2.55)$ \\
\hline Personal Harm & $47 \quad(3)$ & $26 \quad(5)$ & $3.00 \quad(1.04)$ & $1.91 \quad(2.59)$ \\
\hline Future Events & $39 \quad(4)$ & $27(4)$ & $2.23 \quad(.99)$ & $1.69(2.26)$ \\
\hline Disasters & $36 \quad(5)$ & $29(3)$ & $2.75 \quad(1.02)$ & $.81(1.75)$ \\
\hline Classmates & $27 \quad(6)$ & $13(8)$ & $2.50 \quad(.95)$ & $3.44 \quad(3.50)$ \\
\hline Performance & $25 \quad(7)$ & $20 \quad(6)$ & $1.76(.88)$ & $1.12(2.01)$ \\
\hline Family & $23 \quad(8)$ & $20(6)$ & $2.54 \quad(1.14)$ & $1.45(1.47)$ \\
\hline Iittle Things & 21 (9) & $18(7)$ & $1.95(.74)$ & $1.33 \quad(2.22)$ \\
\hline Money & $19(10)$ & $17(7)$ & $2.32(1.00)$ & $.74 \quad(1.10)$ \\
\hline War & $18 \quad(11)$ & $17(7)$ & $2.81 \quad(1.28)$ & $.62(.81)$ \\
\hline Appearance & $17(12)$ & $13(8)$ & $2.18 \quad(1.01)$ & $1.18 \quad(2.40)$ \\
\hline Friends & $10 \quad(13)$ & $9 \quad(9)$ & $2.10(1.10)$ & $2.10 \quad(2.96)$ \\
\hline Other & $6(14)$ & $4(10)$ & $2.67 \quad(1.63)$ & $.50 \quad(.55)$ \\
\hline
\end{tabular}

Note: Calculations are based on 59 children

${ }^{a}$ Ranks are in parentheses

${ }^{\mathrm{b}} \mathrm{Means}$ and standard deviations (in parentheses) 
Table 2

Specific Types of Worry Reported by Total Sample

Area $^{a}$

No. of Responses $\%$ of Responses

(1) School

Performance

Being Called on

Teachers

(2) Performance

Sports

General

Music

Dance

(3) Kids in Your Class

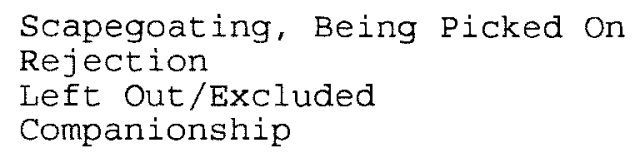

$\begin{array}{ll}9 & 33 \\ 6 & 22 \\ 5 & 19 \\ 4 & 15\end{array}$

(4) Friends

Left Out/Excluded Companionship

Rejection

Betrayal

General

(5) War

Dying/Getting Killed General

(6) Disasters

Hurricanes, Floods, Tornados

(7) Money

Not Enough for Necessities

Parent Unemployed/Lose Job

Not Enough for Luxuries 
(8) Health

Someone Else's Health

Getting Sick (other than AIDS)

Bodily Symptoms (e.g., Nausea)

Going for Medical Care

Dying (Others)

Operations/Surgery (Self)

Getting AIDS

$\begin{array}{rr}18 & 30 \\ 15 & 25 \\ 9 & 15 \\ 5 & 08 \\ 3 & 05 \\ 3 & 05 \\ 2 & 03\end{array}$

(9) Future Events

School Related

(e.g., starting school)

Medical (e.g., seeing a doctor)

Family Related

$12 \quad 31$

3

08

(10) Personal Harm

Personal Harm from others 42

89

(e.g., being robbed)

Accidents

Psychological Fears (e.g., aliens)

2
2

04

04

(11) Little Things

General

Social-Oriented

(e.g., harming others)

Non-Social Oriented

(e.g., being late)

Social-Oriented (e.g., harming self)

$8 \quad 38$

$6 \quad 29$

$5 \quad 24$

$2 \quad 09$

(12) Appearance

General Appearance (e.g., hair) $\quad 6 \quad 35$

Not Good Looking Enough $\quad 5 \quad 29$

Too Fat

Too Short

Too Skinny

$3-18$

$2-12$

106

(13) Family

Parents Might Break Up

Parents Arguing

Sibling Issues

14

61

626

Other

Existential Issues

6

100

${ }^{a}$ Each area is listed in the order that it appeared on the structured interview. Only specific worries that represented $4 \%$ or more of the responses in a particular area are listed with the exception of Health. The term General refers to worries that represent less than $4 \%$ of responses in a particular area, as well as nonspecific responses for each area. It is employed when the sum of those worries were calculated to equal $10 \%$ or more of responses for an area. 
Table 3 .

Summary of Worries: Children without $O A D$

\begin{tabular}{|c|c|c|c|c|}
\hline Area & $\begin{array}{l}\text { No. of } \\
\text { Responses }\end{array}$ & $\begin{array}{l}\text { No. of } \\
\text { Children }\end{array}$ & $\begin{array}{l}\text { Intensity } \\
\text { of Worry }\end{array}$ & $\begin{array}{l}\text { Frequency/ } \\
\text { Event }^{\mathrm{b}}\end{array}$ \\
\hline School & 15 (1) & 11 (1) & $2.40 \quad(.91)$ & $1.79(2.61)$ \\
\hline Health & 14 (2) & $9(2)$ & $2.85(.80)$ & $1.38 \quad(2.72)$ \\
\hline Disasters & 12 (3) & 11 (1) & $2.42(.79)$ & $.83(1.11)$ \\
\hline Personal Harm & $12(3)$ & $8(3)$ & $3.42(1.00)$ & $2.92 \quad(3.45)$ \\
\hline Classmates & $8 \quad(4)$ & $4 \quad(7)$ & $2.50(.93)$ & $4.25 \quad(4.77)$ \\
\hline Performance & $7 \quad(5)$ & $7(4)$ & $2.00(.58)$ & $.50(.55)$ \\
\hline Family & $7 \quad(5)$ & $7 \quad(4)$ & $1.83(1.17)$ & $1.00 \quad(1.09)$ \\
\hline Future Events & $7(5)$ & $6(5)$ & $2.43 \quad(.98)$ & $1.57 \quad(3.73)$ \\
\hline Money & $6 \quad(6)$ & $6 \quad(5)$ & $2.17(1.17)$ & $.50 \quad(1.22)$ \\
\hline Little Things & $6 \quad(6)$ & $6 \quad(5)$ & $1.67(.52)$ & $.33(.52)$ \\
\hline War & $5 \quad(7)$ & $5 \quad(6)$ & $3.25(.96)$ & $.50 \quad(.58)$ \\
\hline Appearance & $5(7)$ & $5(6)$ & $2.40 \quad(1.14)$ & $2.20 \quad(4.38)$ \\
\hline Friends & $2(8)$ & $2(8)$ & $2.00 \quad(.00)$ & $1.00 \quad(.00)$ \\
\hline Other & $1(9)$ & $1 \quad(9)$ & $.00 \quad(.00)$ & $.00 \quad(.00)$ \\
\hline
\end{tabular}

Note: Calculations are based on 26 children

${ }^{a}$ Ranks are in parentheses

Means and standard deviations (in parentheses) 
Table 4.

Summary of Worries: Children with OAD

\begin{tabular}{|c|c|c|c|c|}
\hline Area & $\begin{array}{l}\text { No. of } \\
\text { Responses }\end{array}$ & $\begin{array}{l}\text { No. of } \\
\text { Children }\end{array}$ & $\begin{array}{l}\text { Intensity } \\
\text { of Worry }\end{array}$ & $\begin{array}{l}\text { Frequency/ } \\
\text { Event }^{b}\end{array}$ \\
\hline Health & $45 \quad(1)$ & $23(1)$ & $2.38 \quad(1.03)$ & $1.20(1.30)$ \\
\hline School & $36(2)$ & $20 \quad(3)$ & $2.54 \quad(1.04)$ & $1.54(.52)$ \\
\hline Future Events & $32 \quad(3)$ & $21(2)$ & $2.19(1.00)$ & $1.72(1.89)$ \\
\hline Personal Harm & $31 \quad(4)$ & $17(5)$ & $2.90 \quad(1.01)$ & $1.32(1.66)$ \\
\hline Disasters & $24 \quad(5)$ & $18 \quad(4)$ & $2.92(1.10)$ & $.79 \quad(2.02)$ \\
\hline Classmates & $18(6)$ & $8 \quad(9)$ & $2.47 \quad(1.01)$ & $2.87 \quad(2.80)$ \\
\hline Performance & $17(7)$ & $12(7)$ & $1.71(.98)$ & $1.35(2.34)$ \\
\hline Family & $16(8)$ & $13(6)$ & $2.81(1.05)$ & $1.62(1.59)$ \\
\hline Little Things & $15 \quad(9)$ & $12 \quad(7)$ & $2.07(.80)$ & $1.73 \quad(2.52)$ \\
\hline War & $13(10)$ & $11(8)$ & $2.67 \quad(1.37)$ & $.67(.89)$ \\
\hline Money & $13(10)$ & 11 (8) & $2.38(.96)$ & $.85(1.07)$ \\
\hline Appearance & $12(11)$ & $8 \quad(9)$ & $2.08 \quad(1.00)$ & $.75 \quad(.87)$ \\
\hline Friends & $8 \quad(12)$ & $7(10)$ & $2.12 \quad(1.25)$ & $2.37 \quad(3.29)$ \\
\hline Other & $5 \quad(13)$ & $3(11)$ & $3.20(1.10)$ & $.60(.55)$ \\
\hline
\end{tabular}

Note: Calculations are based on 33 children

${ }^{a}$ Ranks are in parentheses

Means and standard deviations (in parentheses) 
Table 5

Specific Types of Worry Reported by Children with OAD

Area $^{\text {a }}$

No. of Responses

$\%$ of Responses

(1) School

Performance
Being Called on
Teachers
General

(2) Performance

Sports

Music

General

(3) Kids in Your Class

Left Out/Excluded

Rejection

Scapegoating, Being Picked on Companionship

General

(4) Friends
18

9

5

4

7

2

8

3

5

7

1

2
50

25

14

11
41

12

47

17

28

39

05

11
Left Out/Excluded

Rejection

Companionship

Betrayal

General

$\begin{array}{ll}2 & 25 \\ 2 & 25 \\ 2 & 25 \\ 1 & 12 \\ 1 & 12\end{array}$

(5) War

Dying/Getting Killed General

10

3

77

23

(6) Disasters

Earthquakes

Hurricanes, Floods, Tornados

(7) Money

Not Enough for Necessities

Parent Unemployed/Lose Job
1

22

04

92

$\begin{array}{ll}7 & 54 \\ 6 & 46\end{array}$ 
(8) Health

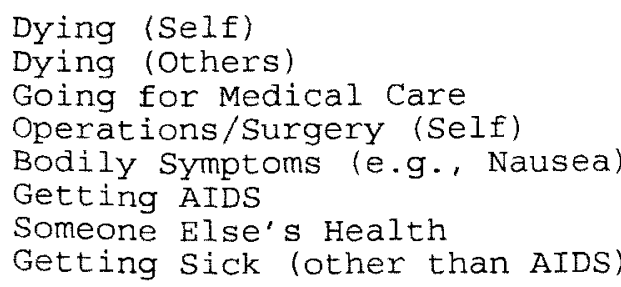

$\begin{array}{rr}1 & 02 \\ 3 & 07 \\ 4 & 09 \\ 2 & 04 \\ 6 & 13 \\ 1 & 02 \\ 13 & 29 \\ 11 & 24\end{array}$

(9) Future Events

Family Related

School Related

(e.g., starting school)

Medical (e.g., seeing a doctor)

General

$\begin{array}{rl}3 & 09 \\ 16 & 50 \\ 8 & \\ 5 & 25 \\ & 16\end{array}$

(10) Personal Harm

Personal Harm from others

(e.g., being robbed)

Accidents

(11) Little Things

Non-Social Oriented

(e.g. being late)

Social-Oriented

(e.g., harming others)

social-Oriented (e.g., harming self)

General

(12) Appearance

Not Good Looking Enough

Too Fat

Too Skinny

Too Short

General Appearance (e.g., hair)

$\begin{array}{ll}4 & 33 \\ 1 & 08 \\ 1 & 08 \\ 2 & 16 \\ 4 & 33\end{array}$

(13) Family

Parents Arguing

Parents Might Break Up

Sibling Issues

$\begin{array}{ll}6 & 37 \\ 8 & 50 \\ 2 & 12\end{array}$

(14) Other

Existential Issues

5

100

${ }^{a}$ Each area is listed in the order that it appeared on the structured interview. Only specific worries that represented $4 \%$ or more of the responses in a particular area are listed with the exception of Health. The term General refers to worries that represent less than $4 \frac{\circ}{6}$ of responses in a particular area, as well as nonspecific responses for each area. It is employed when the sum of those worries were calculated to equal $10 \%$ or more of responses for an area. 
Table 6

Specific Types of Worry Reported by Children without OAD

Area $^{a}$

No. of Responses \% of Responses

(1) School

Performance

Being Called On

Teachers

11

2

73

General

(2) Performance

Sports

General

(3) Kids in Your Class

Left Out/Excluded

Rejection

Scapegoating, Being picked on

Companionship

General

(4) Friends

Left Out/Excluded

Companionship

(5) War

Dying/Getting Killed General

$3 \quad 60$

240

(6) Disasters

Hurricanes, Floods, Tornados

(7) Money

Not Enough for Necessities

Not Enough for Luxuries

Parent Unemployed/Lose Job

$\begin{array}{ll}3 & 50 \\ 1 & 17 \\ 2 & 33\end{array}$


(8) Health

Going for Medical Care

Operations/Surgery (Self)

Bodily Symptoms (e.g., Nausea)

Someone Else's Health

Getting Sick (other than AIDS)

$\begin{array}{ll}1 & 07\end{array}$

107

321

$5-36$

429

(9) Future Events

School Related

1

14

(e.g., starting school)

Medical (e.g., seeing a doctor)

4

57

General

2

29

(10) Personal Harm

Personal Harm from others

11

92

(e.g., being robbed)

Psychological Fears (e.g., aliens)

1

08

(11) Little Things

Non-Social Oriented

(e.g., being late)

Social-oriented

(e.g., harming others)

General

(12) Appearance

Not Good Looking Enough

Too Fat

General Appearance (e.g., hair)

120

240

240

(13) Family

Parents Might Break Up

General

(14) Other

Existential Issues

0

${ }^{a}$ Each area is listed in the order that it appeared on the structured interview. Only specific worries that represented $4 \%$ or more of the responses in a particular area are listed. The term General refers to worries that represent less than $4 \%$ of responses in a particular area, as well as nonspecific responses for each area. It is employed when the sum of those worries were calculated to equal $10 \%$ or more of responses for an area. 
Figure 1

Age and Severity of Children's Worries

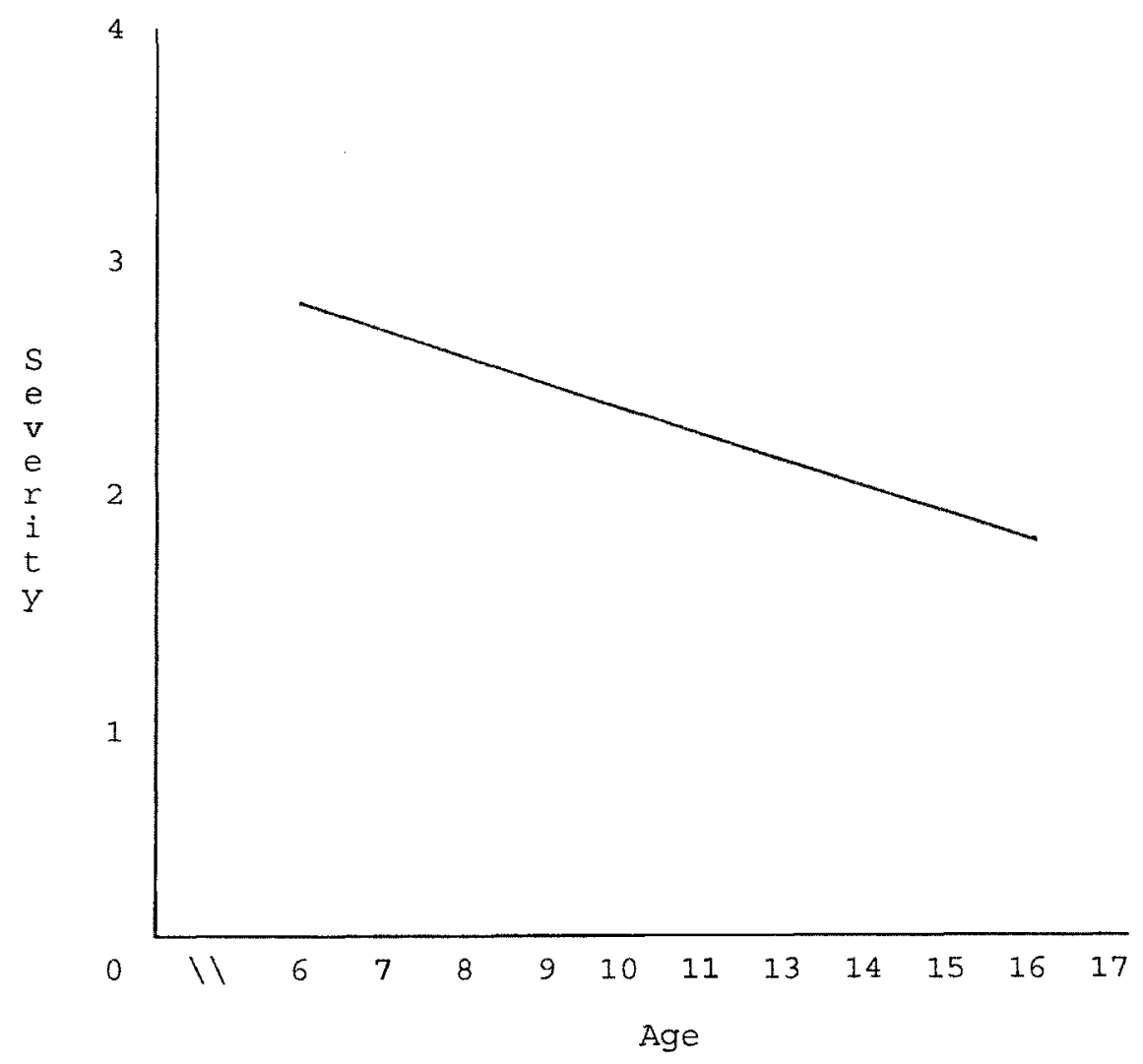


Figure 2

Age and Number of Children's Worries

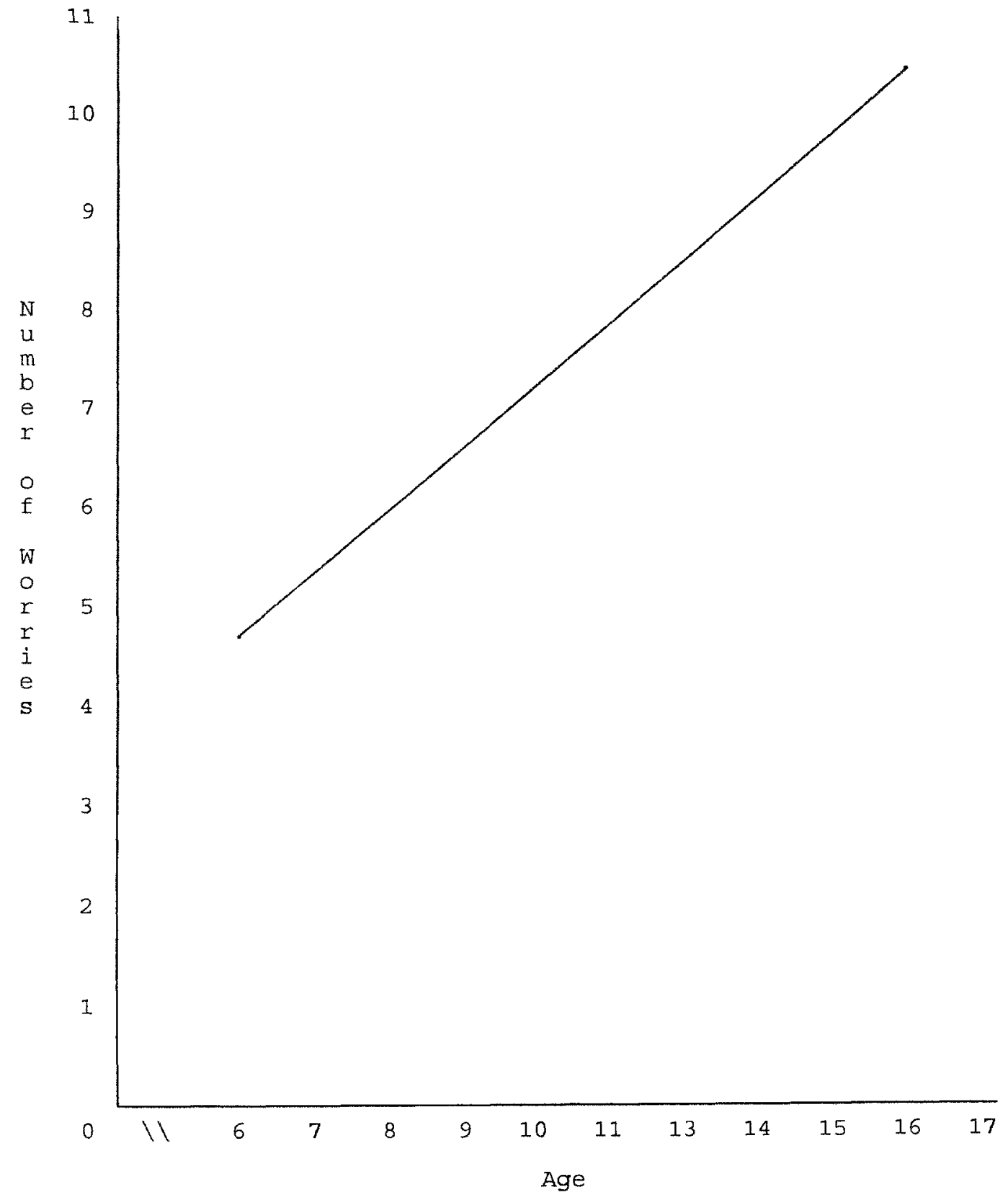


Figure 3

Worry and the Effects of Age and Gender

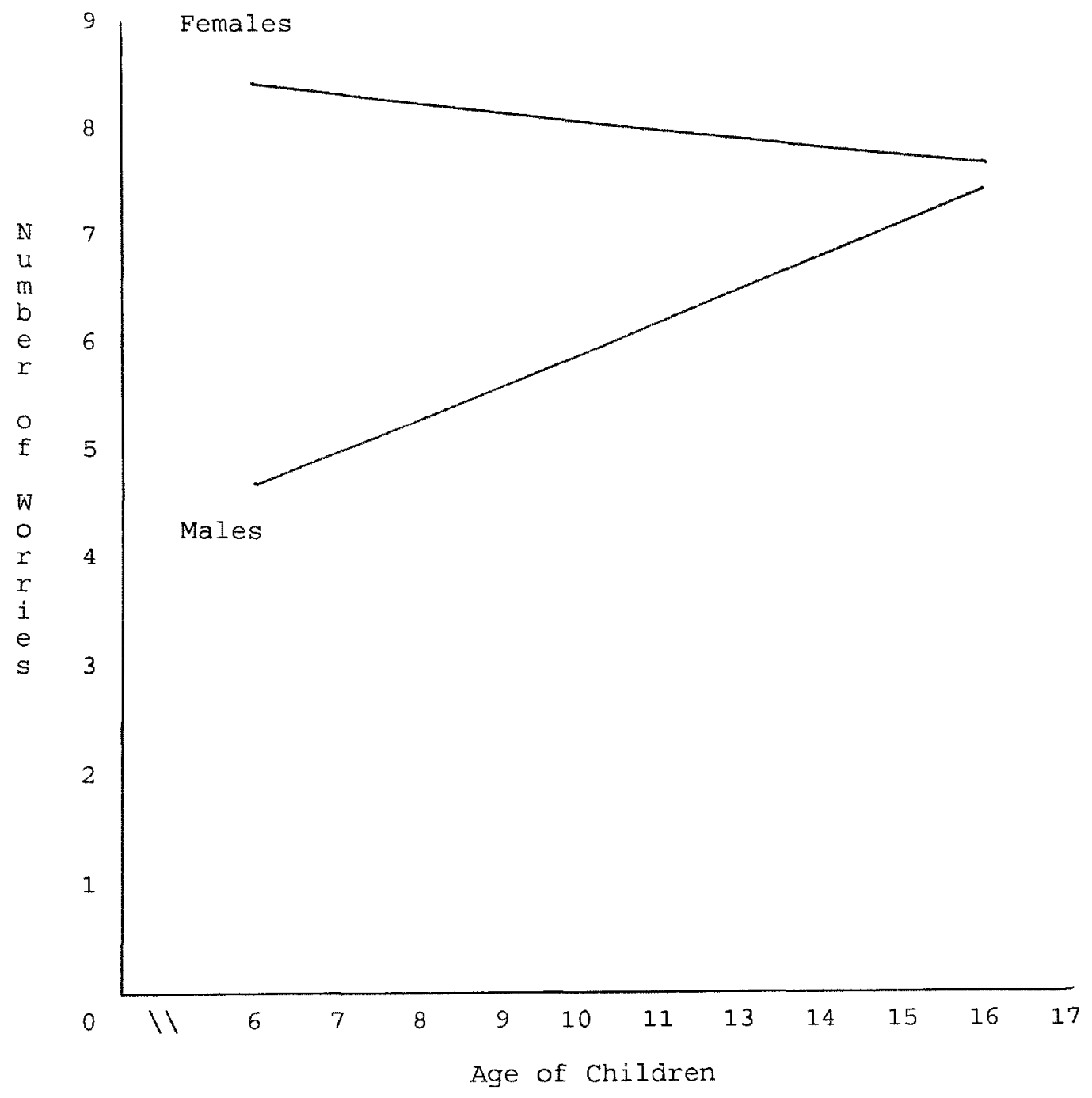


Figure 4

Worry Reported by Children with and without OAD During

\section{Childhood or Adolescence}

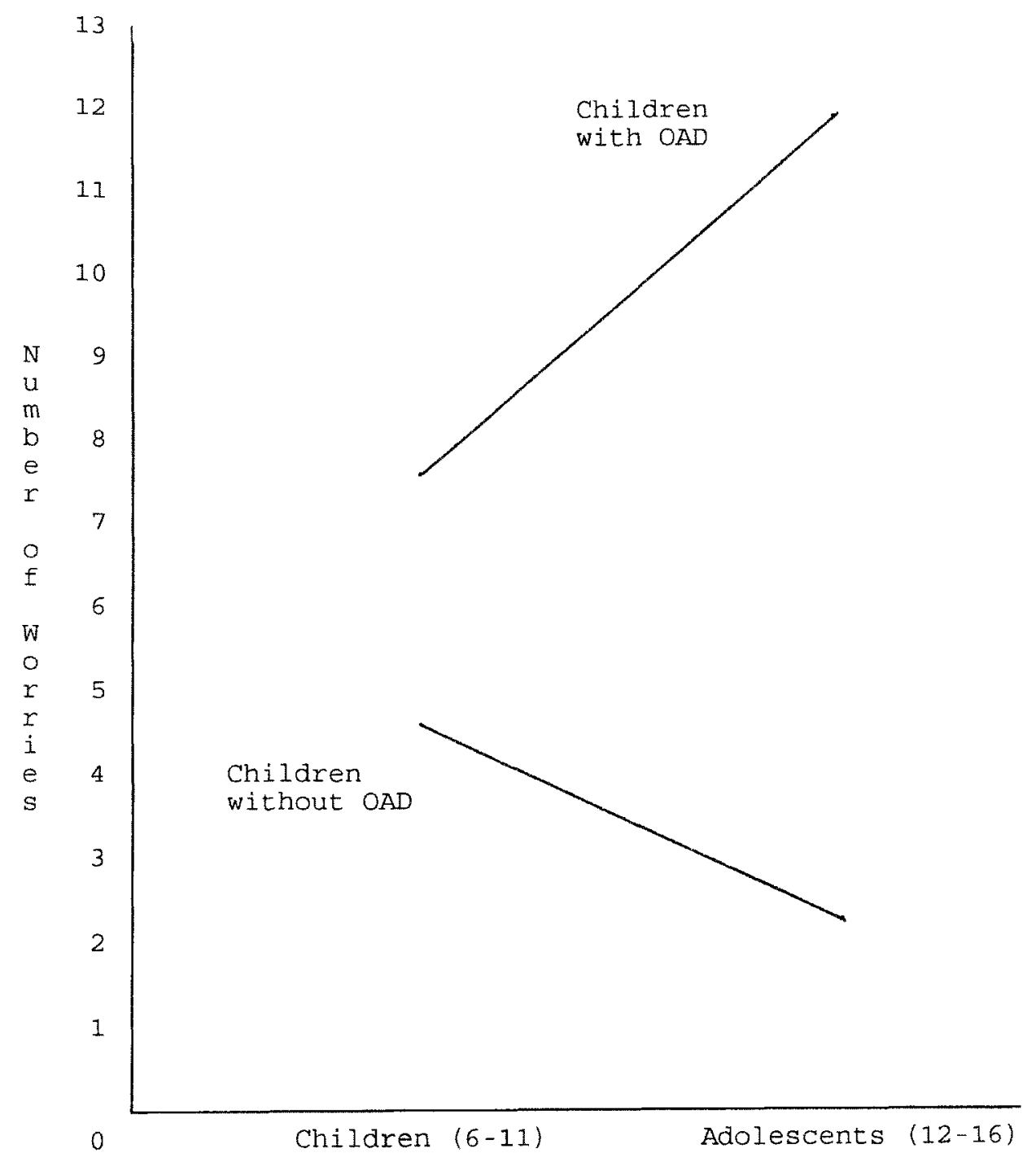


Figure 5

Areas of Worry Reported by Children with and without OAD During

\section{Childhood or Adolescence}

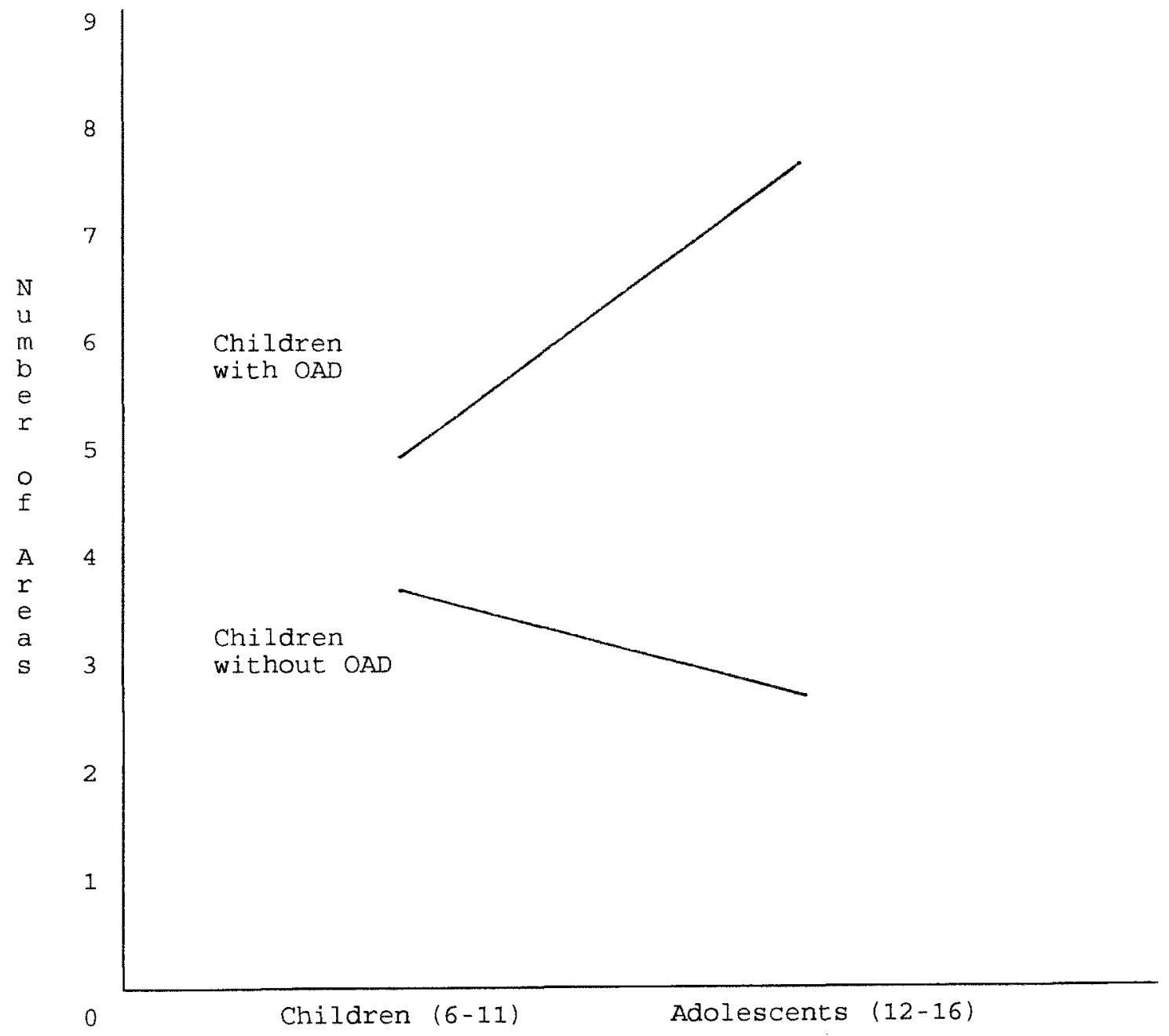

